\title{
El bricoleur y la ciudad: Juan Antonio Ramírez y el ecosistema del arte en Málaga. 1980-2000
}

Tempranamente fallecido en 2009, Juan Antonio Ramírez había sido una figura proteica y heterodoxa. Además de textos académicos y de divulgación, firmó también obras de narrativa y poesía, y tenía una faceta mucho menos conocida vinculada a la creatividad plástica. Precisamente a esta actividad paralela se ha dedicado la exposición El Bricoleur y la ciudad, celebrada en la Sala de Exposiciones del Rectorado de la Universidad de Málaga, comisariada por Rocío de la Villa y Maite Méndez Baiges y con un diseño de sala de Diego Santos. La muestra plantea el encuentro humano en la ciudad como una constante, presentando a Juan Antonio Ramírez como un nodo dentro de un grupo de personas que se divertían entre la vida y el arte. Las piezas trazan un subtexto de amistad, un relato de varios amigos que se cruzaron en un momento en el que coincidía su propia juventud con una coyuntura histórica ilusionante.

Casi por accidente, Juan Antonio Ramírez había nacido malagueño. Sin embargo, su verdadera relación con la ciudad tendría lugar a partir de 1980, cuando llegó allí para convertirse en uno de los catedráticos más jóvenes del Estado. Su creatividad y su sentido del humor fueron bien acogidos en la Málaga de los ochenta: el historiador del arte -quien firmaba como JAR- comenzaría una etapa enormemente productiva, emprendiendo diversos caminos creativos que hubieran sido imposibles sin un entorno cómplice. En la exposición de la UMA, cuatro proyectos estructuran la muestra, funcionando como géneros creativos y poniendo en diálogo las invenciones de Juan Antonio Ramírez con el contexto de la ciudad andaluza.

\section{Happening}

Quizás uno de los eventos colaborativos más sorprendentes sea La ascensión del Guernica a los cielos, cuya documentación abre la muestra de El bricoleur y la ciudad [1]. Este «happening picassiano» ya había sido anunciado en la revista Boletin de Arte, y se materializó el 24 de junio de 1981 con una suerte de performance-procesión que festejaba irónicamente el retorno del Guernica a España. Convocando a una banda local de música y a un grupo de «desfilantes», se exhibían unos ingrávidos cubos de papel llenos de globos, pintados con imágenes alusivas a la obra picassiana. Uno de estos cubos-cubistas diseñados por Gabriel Padilla, ha podido reconstruirse para la exposición de la UMA, mostrándose suspendido entre el suelo y el techo. En esta performance política, bajo la apariencia de festividad, se dejaba ver una burla a la canonización de la obra de Picasso y una crítica a la utilización del arte contemporáneo como estrategia de auto-celebración por parte de la joven democracia española. En ese sentido, La ascensión del Guernica a los cielos puede leerse como una acción precursora relacionada con las que posteriormente organizarían grupos como la Fiambrera Obrera o Yo Mango. Su alegría, por otra parte, estaba claramente vinculada a su propio momento, y formaba parte de ese clima general de humor y desenfado que constituía la versión malagueña de la Movida.

\section{Mobiliario}

Bautizado como el Templicón, entre 1982 y 1985 JAR construiría un lúdico mueble con forma de templo, cuya génesis se relacionaba también la posmodernidad malagueña. No es difícil ver el armario-templo como un reverso juguetón de las investigaciones que habían ocupado sus energías en el Instituto Warburg de Londres durante el curso 1979-80, centradas en rastrear las diversas especulaciones arquitectónicas que habían tratado de reconstruir el Templo de Salomón. El propio nombre del mueble asimismo es un juego con los vocablos del «templo» y el «icono» [2]. Además de diseñar y construir físicamente el mueble, JAR realizó una especie de tratado explicando un complejo programa iconográfico en la tradición de los libros de emblemas. Enlazando de nuevo con Málaga, dicho programa sería ejecutado por los pintores Carlos Durán, Gabriel Padilla, Pepe Seguiri y Antonio Olveira, 


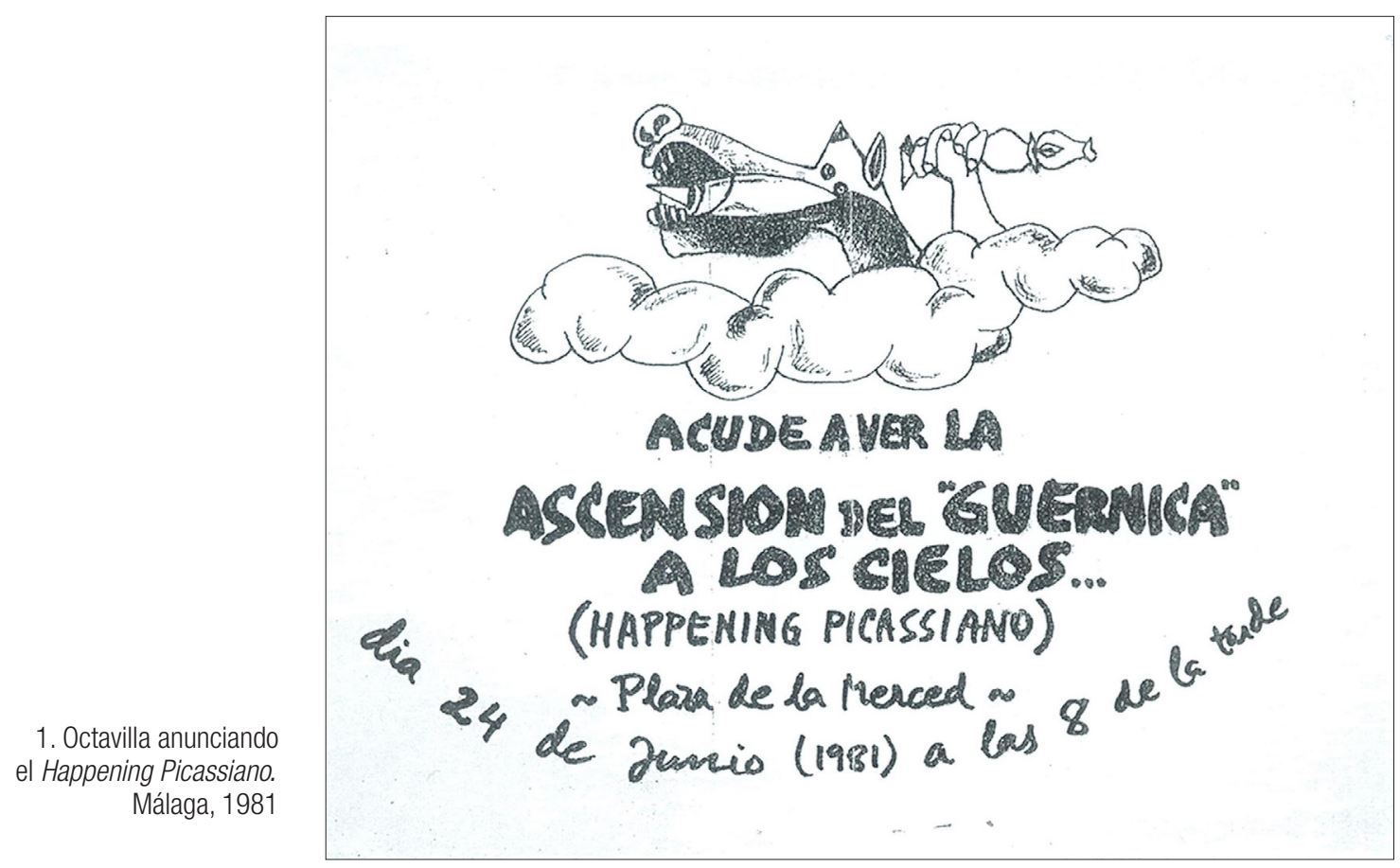

de los que la UMA muestra también otras obras. En un dialogo estimulante con otros objetos, se pone en evidencia la riqueza de una «escuela» local con identidad propia.

\section{Arquitectura del relax}

No parece improbable que el Templicón estuviese en cierto modo inspirado por la arquitectura ecléctica de la Costa del Sol, entregada a un negocio turístico que producía estéticas afines a las celebradas por Venturi en Aprendiendo de las Vegas. En Málaga, el historiador del arte acuñaría el término del estilo del Relax para referirse a las formas de la edificación costera, cuyo hedonismo constituía una suerte de decorado cinematográfico para las vacaciones en el Mediterráneo. La apreciación de su sentido podría haber estar influenciado por la estancia que durante el curso de 198283 llevó a JAR a Nueva York para estudiar la historia de la arquitectura del cine.

A partir de una idea de Diego Santos, se realizaría en 1987 una exposición llamada El estilo del relax, cuyo catálogo incluyó fotografías de Carlos Canal y textos de Juan
Antonio Ramírez. Agotada esta edición, en 2010, la profesora Maite Méndez y otros colegas continuarían el proyecto con una nueva muestra, así como con la publicación de una caja que contenía la edición facsímil de 1987 y un segundo volumen titulado El relax expandido. La Economía turística en Málaga y la Costa del Sol. La exposición de 2018 ha puesto en diálogo estas dos iniciativas con obras de otros artistas del entorno, vinculados a corrientes neo-dadaístas y conceptuales, como son José de la Calle, Francisco Chica o Agustín Parejo School.

\section{Esculturas de lata}

Lo cierto es que Málaga ha sido la única ciudad en la que Juan Antonio Ramírez, en repetidas ocasiones, ha exhibido sus creaciones plásticas. Precisamente allí había mostrado (hasta ahora) por única vez sus esculturas hechas de latas de conservas. JAR se había iniciado en esta práctica durante su estancia en Los Ángeles durante el curso de 1991-1992 donde en el Getty Research Institute estaba investigando en torno a la obra de Duchamp. La primera finalidad de estos 


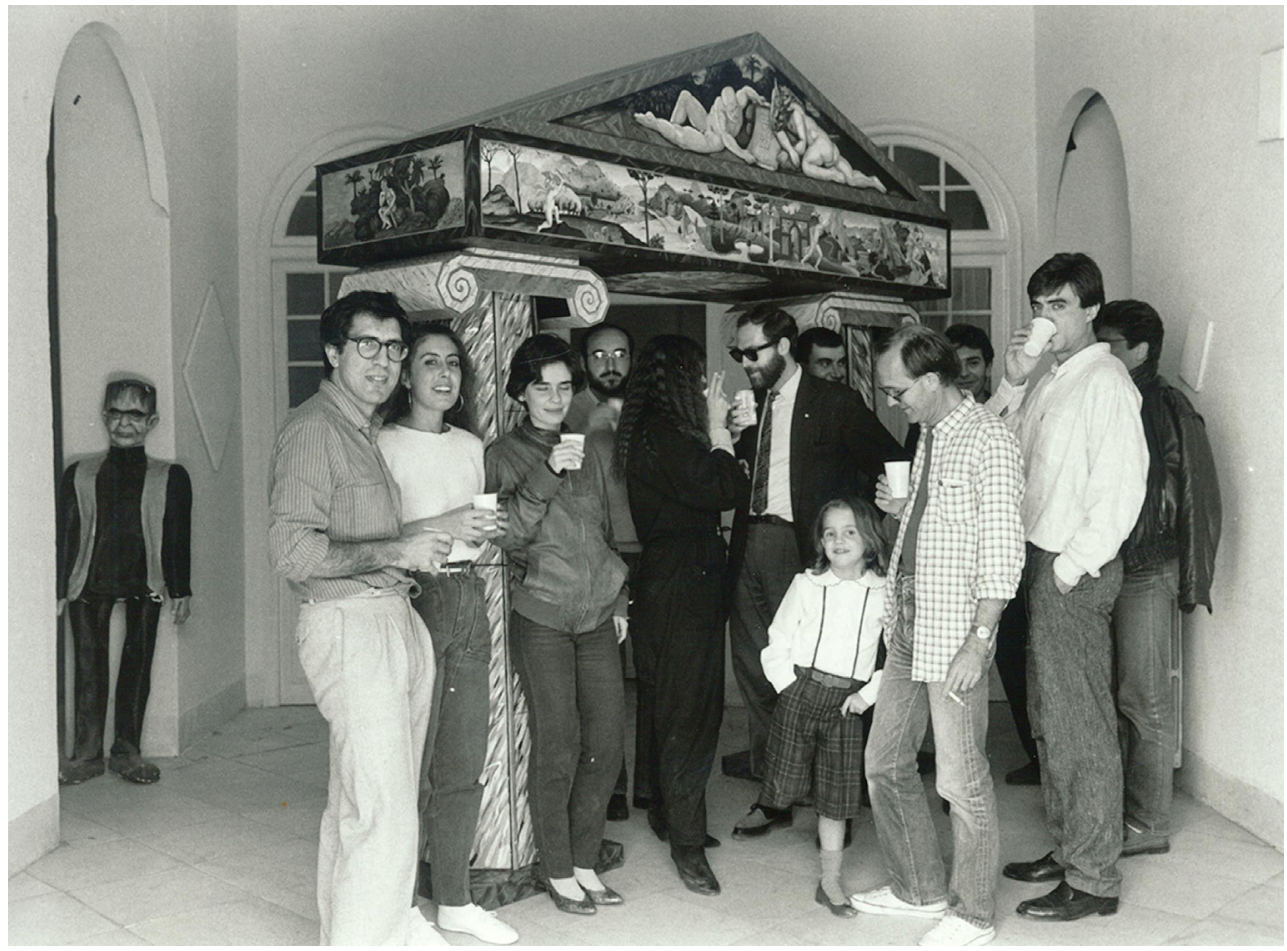

2. Presentación del Templicón en Villa Suecia, 1985, fotografía de Bernardo Pérez (de izquierda a derecha: JAR, Sonia Luna, Tecla Lumbreras, Francisco Chica, María, Andrés García Cubo, Pepe Seguirí, Pepe Oyarzabal y su hija, Carlos Durán, Bernardo Pérez y Gabriel Padilla)

objetos era la de jugar con su hija, que por entonces tenía cinco años, convirtiendo en juguetes aquellos envases vacíos que habían contenido alimentos.

Para la exposición de este nuevo arte, en el 2000 realizó una edición limitada de un «kit» a lo Fluxus, cuya maleta metálica contenía unas tijeras de podar utilizadas para cortar las latas, un martillo, un punzón, un trocito de madera, una lata y unos guantes de jardinería para proteger las manos. Dentro de esta caja de herramientas también había un pequeño libro titulado Latoflexia y latotomía. Tratado breve, cuyo nombre de nuevo evocaba el gusto por la tradición tratadística invocada ya en el Templicón. La invención de la palabra latoflexia aludía a la papiroflexia y en el fondo escondía una crítica contra el academicismo pretencioso y pedante. Este tratado sui generis constaba de ilustraciones del propio Ramírez donde explicaba cómo hacer los distintos prototipos de animales, siguiendo esquemas sencillos que permitiesen a cualquiera replicar las «piezas».

\section{Lámparas de lata}

Al publicar su Tratado, JAR declaraba el nacimiento del nuevo arte como «hijo de la escultura dadaísta y de la eterna pulsión humana por fabricar juguetes intrascendentes». Sin embargo, estas construcciones se expandieron también hacia el diseño de objetos más «funcionales»: en la reciente muestra de la UMA, pudieron verse por vez primera un conjunto de siete lámparas de lata y un aplique de pared originalmente realizados para una casa de verano. Este conjunto de 1995 fue concebido como una totalidad, y cada pieza se relacionaba con una habitación concreta. En estas lámparas, generalmente el cuerpo o la arquitectura de la lámpara está definido por tambores superpuestos de latas sin recortar. De allí cuelgan diferentes figuras de lata, incorporando también juguetillos de plástico adquiridos en tiendas de chucherías. Como sucedía con los juguetes, la dimensión escultórica de nuevo tiene que ver con el 


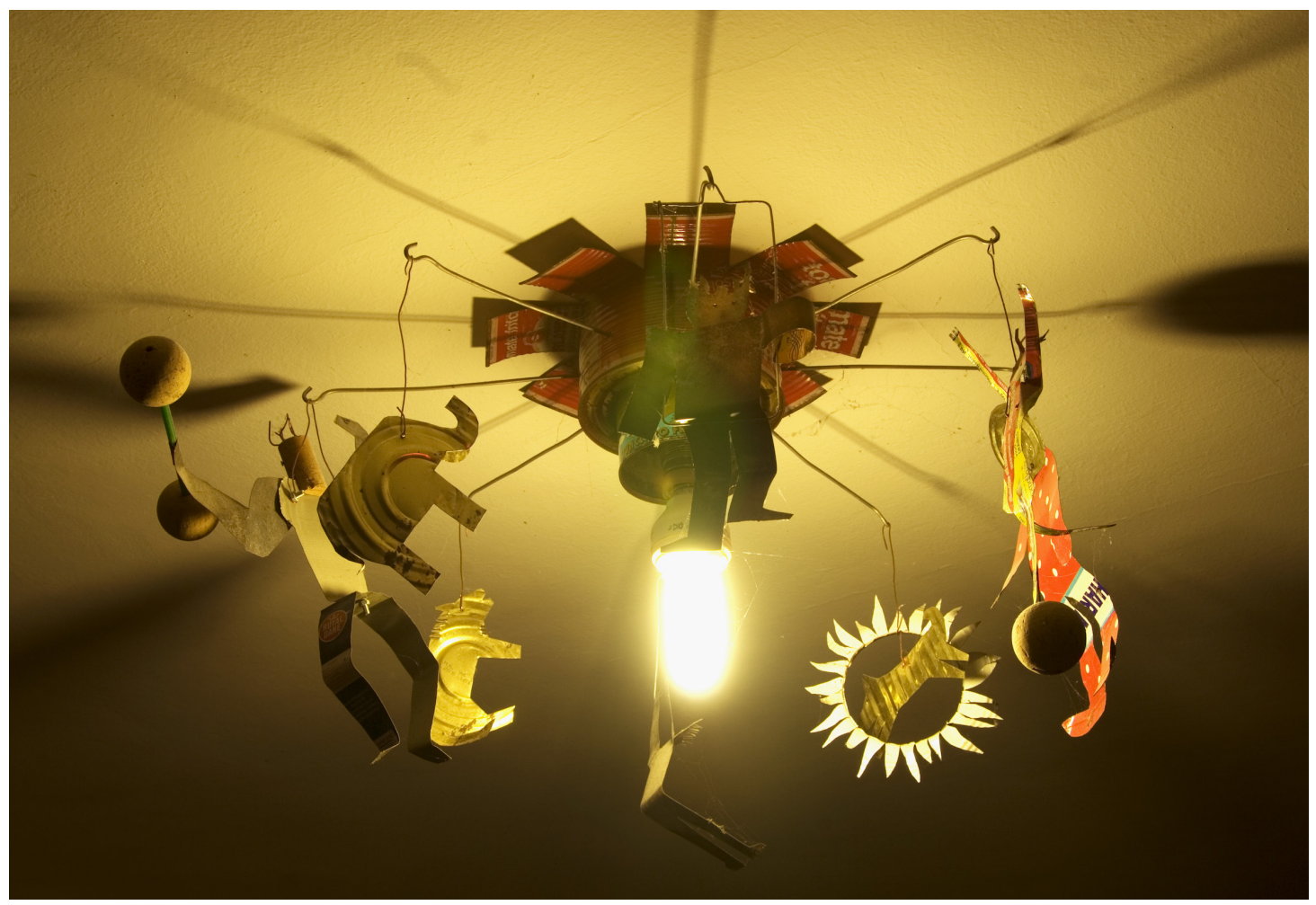

3. Juan Antonio Ramírez, Lámpara circense, 1995

ready-made en su lectura más pop. En ellas, JAR pone en relación diferentes objetos encontrados con las latas y sus letras o imágenes estampadas.

Para el salón de la casa JAR había concebido una lámpara homenajeando a Calder: en torno a dos tambores de lata, se disponían de manera circular figuras circenses, como un forzudo levantando pesas, un equilibrista en un columpio o un perro cruzando un aro de fuego [3]. En la escalera, se situaba un aplique de pared de forma aviaria, un Pájaro lunar que remitía a sus propios juguetes zoomorfos. La Lámpara de enmarañamientos del dormitorio podría haberse referido a la ambivalencia entre el sueño y la pesadilla, así como a los laberintos del inconsciente. En el dormitorio infantil, las formas de la lata recortada trazaban las figuras de varios muñecos y, al relacionarse con la luz, convertían la pared en un teatro de sombras. Concebida para un segundo dormitorio, la Lámpara estrellada era de una gran sencillez, y su color plateado parecía evocar las representaciones tradicionales de la luna.

\section{Arte y vida}

La noción de una creatividad que altera el entorno doméstico tiene una estrecha relación con la posición intelectual de Juan Antonio Ramírez como historiador del arte, que entendía la creatividad plástica como una forma de ensanchar la vida cotidiana. JAR siempre quiso llevar a cabo la promesa de las vanguardias de la democratización del arte, y desarrollar el axioma de Joseph Beuys que afirma que todo ser humano es un artista. Su producción plástica también se vincula a su gusto por el arte marginal, y su interés por la creatividad de los no-artistas, a los que dedicó un libro y una asignatura en la universidad. Para él este principio de democratización afectaba tanto a la creación como al disfrute del arte y estaba intrínsecamente ligado a una posición ideológica unida a la izquierda política. También vinculada a su labor manual se situaba su gusto por la lectura y su comprensión de la disciplina como un particular género literario y, por tanto, una actividad creativa. La exposición malagueña 
muestra de manera clara la relación entre los proyectos de investigación y la actividad bricoleur de Juan Antonio Ramírez quien, en privado y con su familia o amigos, ponía a jugar las ideas. Inseparables de la emoción del disfrute y del juego, sus obras suponían la expansión del proceso de pensamiento hacia la actividad de las manos.

La inauguración de la exposición en la UMA fue una fiesta, donde la inclusión de la tuna recordaba a la procesión urbana de la Ascensión del Guernica a los cielos. Y tras la clausura de la muestra, a través de una cesión temporal permanecerán en Málaga el Templicón (en el Museo de la Aduana) y las siete lámparas y el pájaro lunar (en el recinto universitario). Queda también, como volumen de referencia, un espléndido catálogo que incluye textos de Rocío de la
Villa, Francisco Chica, Rosario Camacho, José de la Calle, Luis Fernández Galiano, Francisco García Gómez, Esteban Pujals, Eugenio Carmona y Maite Méndez Baiges. De cuidado diseño, empleando la tipografía de máquina de escribir que JAR utilizaba en sus manuscritos, la edición incluye la reproducción del librito del Templicón y el mapa del Estilo del Relax, que lo convierten también en un objeto de artista, continuando la labor de reedición en facsímil y la continuación de los proyectos más experimentales de Juan Antonio Ramírez por parte de la UMA. A veces, la complicidad entre un autor y un lugar puede seguir desarrollándose después de la muerte, incluso.

Julia Ramírez Blanco

\section{Bibliografía}

DE LA VILLA, Rocío y MÉNDEZ BAIGES, Maite (eds.) (2018), El bricoleur y la ciudad. Juan Antonio Ramírez y el ecosistema del arte en Málaga 1980-2000, Universidad de Málaga, Málaga.

MÉNDEZ BAIGES, Maite (ed.) (2010), El relax expandido. La Economía turística en Málaga y la Costa del Sol, Observatorio de Medio Ambiente Urbano y Colegio de Arquitectos de Málaga, Málaga.

VENTURI, Robert y BROWN, Denise Scott (1978), Aprendiendo de las Vegas, Gustavo Gili, Barcelona.

RAMíREZ, Juan Antonio (1983), Construcciones ilusorias. Arquitecturas descritas, arquitecturas pintadas, Alianza, Madrid.

- (1991), Dios, arquitecto, Siruela, Madrid.

- (1994), Ecosistema y explosión de las artes, Anagrama, Madrid.

- (1996), Cómo escribir sobre arte y arquitectura. Libro de estilo e Introducción a los géneros de la crítica y de la historia del arte, Barcelona, Ediciones del Serbal.

- (2000), Latoflexia y latotomía. Tratado breve, Málaga, Área de Cultura, Ayuntamiento de Málaga, Málaga (edición facsímil (2012), Málaga).

- (2006), Escultecturas margivagantes. La arquitectura fantástica en España, Siruela, Madrid.

- (1987), El Estilo del relax. N-340, Colegio de Arquitectos de Málaga, Málaga. 